\title{
Reconocimiento del derecho a la educación en las constituciones de México 1812 a 1917
}

\author{
Right to Education: its development in Mexican \\ Constitutions, 1812 to 1917

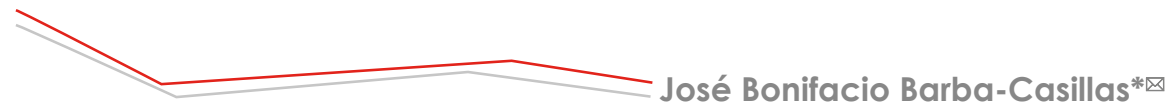

Barba-Casillas, J. B. (2019). Reconocimiento del derecho a la educación en las constituciones de México 1812 a 1917. Investigación y Ciencia de la Universidad Autónoma de Aguascalientes, 27(76), 60-69.

\section{RESUMEN}

México vive una exigencia social creciente de realización del derecho a la educación, el cual tiene una historia constitucional vinculada a la definición de la estructura y fines del Estado mexicano. Este trabajo expone la construcción normativa de este derecho enmarcándolo en una visión de las dimensiones de la cultura. Tomando como aspecto central la dimensión jurídica, se analiza la historia constitucional del país para identificar las fases de la organización del Estado y exponer la construcción paulatina del derecho a la educación, tanto en las constituciones como en la legislación secundaria derivada de ellas. Se concluye que México se ha formado con fundamento en el proyecto de Estado democrático de derechos y que en las transiciones del país el reconocimiento del derecho a la educación es una constante preocupación social y

Palabras clave: México; derecho a la educación; constituciones mexicanas; Estado mexicano; dimensiones jurídicas de la cultura; legislación educativa.

Keywords: Mexico; right to education; Mexican constitutions; Mexican state; cultural legal dimensions; educational legislation.

Recibido: 13 de febrero de 2018, aceptado: 18 de septiembre de 2018

* Departamento de Educación, Centro de Ciencias Sociales y Humanidades, Universidad Autónoma de Aguascalientes. Av. Universidad 940, Cd. Universitaria, C. P. 20131, Aguascalientes, México. Correo electrónico: jbbarba@correo.vaa.mx. ORCID: http://orcid.org/0000-0002-85133085.

$凶$

Autor para correspondencia política que lo hace un elemento clave del proyecto jurídico de nación y de formación ciudadana.

\section{ABSTRAC1}

Mexico is having an increasing social demand of educational rights which has a constitutional history linked to the structure and purposes of the Mexican Government. This study discusses the normative construction of this right from a cultural perspective. Focusing on the legal dimension, the constitutional history is analyzed in order to identify the stages of the State organization, and to explain the gradual construction of educational rights in the constitutions as well as in the secondary legislation which is derived from them. It is concluded that Mexico has been formed based on a project of democratic state of law, and on government's transitions, the recognition of the right to education has been a persistent social and political concern, making it a key element in the legal project of nation and citizen education.

INTRODUCCIÓN

Paradójicamente y como señal de las contradicciones en la creación, vivencia, protección y transformación de la cultura en la sociedad mexicana, a las políticas que produjeron la limitación del Estado de bienestar desde la década de los ochenta del siglo $X X$, se les ha opuesto una creciente demanda social por reconocer, ampliar y garantizar el derecho a la educación (a partir de aquí DEd), considerando tanto el trabajo escolar como la gestión del complejo sistema educativo; ese es el sentido de la reforma del artículo $3^{\circ}$ constitucional en 2013 (Cámara de Diputados, 2013). Estas condiciones son necesarias y 
exigibles para el desarrollo humano de los educandos, la satisfacción de las necesidades sociales y la consolidación de la democracia como forma de vida, según lo estableció la reforma del artículo $3^{\circ}$ constitucional en 1946. Esta cuestión forma parte de los principios y valores que contiene el actual texto del artículo $3^{\circ}$ constitucional y que el artículo $7^{\circ}$ de la Ley General de Educación (LGE) recoge, precisa y actualiza. Es por ello pertinente mostrar el proceso histórico de reconocimiento del DEd; es decir, responder a la pregunta de cómo se fue desarrollando este derecho en las constituciones y en la legislación de México, pues este derecho "ocupa un lugar central en el constitucionalismo mexicano" (Valadés, 2016, p 33).

El momento actual de la experiencia social e institucional mexicana no es un fenómeno aislado en la historia del país que se agote en los tiempos de la circunstancia, sino que es la expresión contemporánea del largo proceso histórico de construcción normativa del DEd y del sistema escolar instituido progresivamente para su realización. Sin embargo, entre las normas jurídicas y la práctica educativa existen contradicciones que limitan la realización del DEd, como lo muestran Aboites (2012), el Instituto Nacional para la Evaluación de la Educación (a partir de aquí INEE, 2010, 2014, 2016), Ruiz Muñoz (2015) y Solís (2010) para la historia reciente y lo hace Galván Lafarga (2016) para toda la vida independiente de México al analizar la formación de las políticas y las instituciones educativas y la insuficiencia de la garantía del mencionado derecho. Esta crisis en la realización del DEd no es exclusiva del mismo, sino que forma parte de "una coyuntura crítica en materia de derechos fundamentales" en México (González Pérez, 2016b, p. 43).

Este proceso de reconocimiento del DEd está ligado de manera intrínseca a la formación de la nación, desde la expresión de la identidad criolla en la reivindicación independentista hasta la formulación del proyecto de sociedad política de acuerdo con la estructura y fines del Estado constitucional surgido de la llustración, ideal que fue recogido y adaptado a las circunstancias de la Nueva España insurgente (Galván Lafarga, 2016; Soberanes Fernández, 2012).

Dado que "Ia política educativa en México se halla ligada a las grandes etapas de nuestro movimiento de liberación" (Labastida, 1979, p. 103), el objetivo del trabajo es exponer los grandes momentos de la construcción normativa del DEd a la educación en México enmarcándolo en una comprensión de la cultura y sus dimensiones, y considerándolo una expresión primordial de la dimensión jurídica. El proceso de construcción del mencionado derecho se entiende como la sucesión de acciones sociales que reconocen la educación como cuestión personal y social relevante para el progreso y la formación del Estado y la juridifican en su Ley fundamental. Este derecho, junto con otros que son reconocidos en coyunturas históricas significativas, está unido al trabajo social de creación de una sociedad de derechos (Fix-Zamudio, 2010). Describir el progreso normativo del DEd ayuda a comprender cómo se formaron las bases de su exigibilidad.

MATERIALES Y MÉTODOS

El trabajo fue documental en tres etapas. Se analizó en primer término un conjunto de obras de la historiografía de México para formular una visión de su formación que se manifiesta en cuatro grandes transiciones en las que interactúan las dimensiones de la cultura. En segundo lugar, con el marco de las transiciones, se analizaron las normas constitucionales de 1812 a 1917, considerando de esta segunda las diversas reformas en materia de educación hasta el 2013. En tercer término, se hizo un recuento de las principales normas de legislación educativa secundaria vinculándolas a la norma constitucional, en cuyo tiempo de vigencia fueron promulgadas destacando su referencia al derecho a la educación.

\section{RESULTADOS}

Como acción social, la educación es un proceso de naturaleza cultural (Abbagnano \& Visalberghi, 1975) que se ha institucionalizado en las sociedades modernas en respuesta a las necesidades sociales, económicas y políticas. Una comprensión de la cultura la expone León-Portilla:

El conjunto de atributos y elementos que caracterizan a un grupo humano, así como cuanto se debe a su creatividad. En lo que concierne a aquello que lo caracteriza, sobresalen sus formas de actuar y vivir, valores y visión del mundo, creencias y tradiciones. En lo que toca a su capacidad creadora, son clave sus sistemas de organización social, económica y religiosa, sus formas de comunicación, adquisición y transmisión de conocimientos, adaptación al medio ambiente y aprovechamiento de sus recursos. En 
este sentido, todo lo que hace y crea un grupo humano es, en última instancia, cultura. (2005, p. 11)

La cultura es un fenómeno multidimensional, pero está referida de modo sustantivo a la creación humana y ésta se centra en la vida y la acción (Frost, 2009). Giménez (2007, p. 428) cita la triple distinción de J-C Passeron: la cultura como modo de vida, como "comportamiento declarativo" o teoría sobre la cultura misma, y la cultura como "repertorio de obras valorizadas, o patrimonio. Aquí se atiende al patrimonio histórico del DEd. La cultura se integra por siete dimensiones por cuya interacción se estructura, expresa y evoluciona como unidad práctica y simbólica: la dimensión social es el asiento o ámbito originario de la vida y las creaciones culturales por las relaciones materiales y simbólicas entre individuos y grupos; las creaciones se expresan en el transcurso del tiempo y van configurando las dimensiones filosófica (la actividad cognitiva del ser humano, que incluye el meta análisis de las formas de conocer y sus fundamentos), religiosa (definición y vivencia de sentidos espirituales de la existencia), internacional (el ámbito de poderes e influencias en el que cada sociedad se plantea un proyecto de identidad e interacción entre Estados), jurídica (el derecho $u$ orden normativo positivo establecido como regulador de la convivencia), político-gubernamental (organización y uso del poder público con proyección o influencia en el conjunto de las interacciones sociales y políticas) y la económica (el aprovechamiento y transformación de la naturaleza para satisfacer las necesidades humanas).

La interacción de las dimensiones entre sí es permanente y se influyen de forma variada para crear los bienes y valores de la cultura y el curso de la vida social. Por ejemplo, en el proceso de independencia en el siglo XIX la dimensión jurídica simbolizó el proceso de transformación de la sociedad que conformó de manera nueva la dimensión político-gubernamental creando un nuevo Estado, lo cual tuvo influencias y consecuencias filosóficas, económicas y religiosas que se expresaron, entre otros ámbitos, en el derecho educativo.

\section{Las transiciones de México}

La formación de la sociedad nacional y de la entidad estatal que es México ha ocurrido en un largo proceso de acción cultural iniciado en el siglo XVI con la conquista de los territorios mesoamericanos por el imperio español. Los tres siglos de vida colonial no son una entidad monolítica o invariante, y a mediados del siglo XVIII inició una transformación del imperio y de la Nueva España, que es el punto de partida para los propósitos de este trabajo. La visión de la formación de México se muestra distinguiendo cuatro transiciones en la perspectiva de la larga duración de Braudel (1968); es decir, la existencia de grandes periodos históricos que se integran por un conjunto de acontecimientos y fases menores que producen y significan una transformación social de amplio alcance. En el proceso histórico de las transiciones que forman a la sociedad y al Estado mexicanos han ocurrido múltiples interacciones de las dimensiones culturales con preeminencia de alguna de ellas en determinadas fases o sucesos dentro de la larga duración. Por ejemplo, las guerras atlánticas fueron un acontecimiento complejo que tuvo influencias favorables y desfavorables de las dimensiones internacional, político-gubernamental y económica en la formación de México.

La primera transición ocurre de mediados del siglo XVIII, con el inicio de las reformas borbónicas, al triunfo de la revolución de Ayutla (1750-1856) y consiste en la formación de una identidad patria que impulsa la emancipación colonial, con la disputa entre un proyecto autonomista y otro independentista en una primera fase, y entre un proyecto de continuidad de la estructura social y otro de destrucción de la herencia colonial, con el reconocimiento de los derechos fundamentales del hombre y la ratificación de la opción federalista antes de la Reforma en una segunda fase.

La segunda transición, entre 1857 y 1910/1916, se inicia con la Constitución de 1857 y la República restaurada y llega hasta el inicio de la Revolución Mexicana o hasta 1916, si se considera el triunfo de los revolucionarios que pugnaron por una nueva constitución. Esta transición está signada por una doble contradicción: primera, la política, en tanto que la Norma de 1857, destacada por haber hecho el reconocimiento de los derechos del hombre como base de las instituciones sociales, fue perdiendo vida o fuerza en el Porfiriato; y segunda, una contradicción social-económica por la limitación de los derechos y las libertades en beneficio de una economía oligárquica que produjo una nueva base, estructura y expresión de la desigualdad en la sociedad mexicana, que fue un poderoso motivo de la Revolución. 
Con la Revolución Mexicana, que destruye la estructura social y política porfiriana, inicia la tercera transición, cuyo alcance es discutido, tanto en la fecha de cierre de este proceso $(1917,1920,1940)$, como en la realización de sus objetivos sociales, hasta la crisis del sistema político en la década de los sesenta (Cosío Villegas, 1947; Meyer, 1992). Esta transición culmina en dicho decenio con las señales de la crisis del sistema político existente, sobre todo en las dimensiones económica y políticogubernamental; en conjunto, significa el fin del orden revolucionario.

La cuarta transición de México se ubica entre la crisis sociopolítica de la década de los sesenta y el presente 2018, y su rasgo de identidad es la construcción social de la democracia frente al autoritarismo del sistema político, por un lado, y la incertidumbre en que se encuentra tal proceso en los últimos años (Meyer, 2013; Rubio, 2018; Woldenberg, 2012) junto con la promisoria experiencia democrática de la elección de 2018, por el otro. Si el fin de la tercera transición no tiene un acontecimiento sobre el cual haya acuerdo entre los historiadores, la represión de 1968 tiene un valor simbólico particular para el cierre de aquella y para el inicio de la cuarta transición. En esta, por acontecimientos de la dimensión social, la políticogubernamental, la internacional y la económica, el país ha vivido lo que Fix-Fierro (2008) llama una transición jurídica, cuyos reformas e instituciones tienen a los derechos humanos como elemento común. Ahí se insertan las reformas relativas al DEd.

Existe una relación esencial entre las transiciones del país, por un lado, y las revoluciones y los proyectos constitucionales que establecieron y aplicaron, por el otro. En la primera transición se establecieron seis normas fundamentales, sin contar la de 1857, que es la Norma eje para la segunda, y a su vez elemento central para su cierre. La tercera transición crea una Constitución que evoluciona según la dinámica e intereses del sistema político que la reforma y adiciona hasta recoger el impulso central de la cuarta: la exigencia social de democracia y respeto a los DH. En suma, si bien las transiciones están unidas a las constituciones, es la débil vida de éstas la fuente del impulso para abrirlas o cerrarlas.

\section{El proceso histórico jurídico de construcción del derecho a la educación}

En este apartado, dando atención central a la dimensión jurídica, se identifica el reconocimiento del DEd en cada norma fundamental y en las principales leyes relativas a cada una de ellas. En la primera transición de la formación de México, por la acción política de diversos grupos y clases sociales, se probaron todas las formas de gobierno y se tuvo la mayor diversidad de leyes fundamentales. Dos fueron previas a la independencia $(1812,1814)$ y cinco posteriores (1822, 1824, 1836, 1843, 1847).

La Constitución de Cádiz (1812) estableció una monarquía moderada para el gobierno del imperio español y aunque no decretó igualdad de derechos para todos los habitantes del imperio, estableció la educación como un asunto del Estado. En su artículo 366 ordena la extensión de la instrucción como institución pública para que se establezcan escuelas de primeras letras en todos los pueblos de la monarquía (Cortes de Cádiz, 1812).

En 1813 la instrucción para el Gobierno Económico-Político de las Provincias ordenó que las diputaciones provinciales y los ayuntamientos crearan escuelas de primeras letras, y el 29 de junio de 1821 el Reglamento General de Instrucción Pública dio directrices para todos los niveles de enseñanza, destacando que los ayuntamientos se encargaran de la educación elemental; el aprendizaje de la lectura y escritura como requisito para la ciudadanía; la libertad para la enseñanza privada, sujeta a supervisión y la creación de una dependencia gubernamental, la dirección general de estudios responsable de la inspección y organización de toda la enseñanza (artículo 92). En síntesis, promovía la educación por ser un bien público.

La Constitución de Apatzingán está enraizada en el nacionalismo criollo y expresó el propósito de dar a la lucha insurgente un orden jurídico que la reivindicara y fortaleciera. La república es afirmada como ideal de paz, libertad y dignidad humana y acierta en afirmar los derechos fundamentales del hombre porque estos deben ocupar el primer lugar «en el orden político» por emanar de su naturaleza, por ser «preexistentes a todo pacto social» (Zárate, 1987, p. 19). El hecho fundacional es que el Congreso Nacional Americano declaró el 6 de noviembre de 1813 que la nación había recobrado el ejercicio de su soberanía.

La cuestión de la educación como derecho está poco desarrollada, pero expresada con suficiencia con respecto a su importancia personal 
y social. El elemento central de la educación en Apatzingán es la declaración de que "La instrucción, como necesaria a todos a todos los individuos, debe ser favorecida por la sociedad con todo su poder" (artículo 39) (Supremo Congreso Mexicano, 1814). Esta visión de la instrucción es una de las formas en que se muestra la influencia de la Revolución Francesa en la Constitución de Apatzingán, pues con palabras similares y mayor extensión se expresó la Constitución francesa del 21 de junio de 1793 en su artículo 22.

El Reglamento Provisional Político del Imperio Mexicano (1822) pretendía dar una constitución formal a la nación y aunque no fue aprobado por el Congreso, con su publicación se dio fin a la vigencia de la Constitución de Cádiz. Estableció los primeros derechos individuales, entre ellos los de libertad, propiedad, seguridad e igualdad legal, a la vez que exigía el "cumplimiento de los deberes recíprocos (artículo 9) (Del Arenal, 2002, p. 140); declaró a la Nación libre, independiente y soberana y reconocía «iguales derechos en las demás que habitan el globo» (artículo 5, en Serrano Migallón, 2009, p. 432), dando con ello un ejemplo de coherencia constitucional.

Iturbide se interesaba por la opinión popular acerca de los asuntos públicos y en función de ello envió a todo el territorio del imperio un cuestionario, el 27 de marzo de 1822, preguntando acerca de varios aspectos, entre ellas "el estado de la ilustración" (González Domínguez, 1999). En el aspecto legal, es significativo que el Reglamento diera atención a la instrucción pública. El artículo 90.2 fijó la obligación de las diputaciones provinciales de "promover la instrucción, la ocupación y moral pública" (De Iturbide, 1822). El Reglamento, coherente con las previsiones legales de los Tratados de Córdoba, estableció varias obligaciones para los Jefes políticos provinciales siguiendo la Instrucción para el Gobierno Económico-Político de las Provincias, en particular, deberían cuidar del "buen régimen de los establecimientos de beneficencia y educación..." (De lturbide, 1822, artículo 54).

El Reglamento estableció además una obligación importante del gobierno a fin de que "con el celo que demandan los primeros intereses de la nación", creara los "reglamentos y órdenes oportunas conforme las leyes, para promover y hacer que los establecimientos de instrucción y moral pública existentes hoy, llenan los objetos de su institución, debida y provechosamente, en consonancia con el actual sistema político" (artículo 99). En suma, no obstante la crisis del gobierno de Iturbide, es significativo que se atendiera al desarrollo de la educación.

La Constitución Federal de los Estados Unidos Mexicanos (1824) tuvo entre sus antecedentes la difusión del federalismo republicano desde el siglo XVIII y la formación de identidades regionales en las provincias de Nueva España. El proceso social y político que condujo hacia el Estado federal se apoyó en la asunción de la soberanía nacional pero aplicada en la conformación de las provincias como partes iguales de una federación. En estos procesos de cambio estaba ya formada una dinámica contradictoria entre intereses provinciales y compromiso real con la formación de la nación y su gobierno. Con la Constitución se recupera el ideal insurgente de la soberanía ya asumida en Apatzingán, para formar una república y, a juicio de los constituyentes mismos, culmina la revolución de Independencia, fase que ocurre al interior del largo proceso del nacimiento de México (1750-1856) (Vázquez, 2002).

El ejercicio de la soberanía que funda el nuevo Estado crea varias áreas de acción para los poderes representativos; una de ellas es 'la ilustración', objeto de atención en la primera facultad del Congreso general, consistente en "promover la ilustración" en diferentes campos de las ciencias, técnicas y artes "sin perjudicar la libertad de las legislaturas para el arreglo de la educación pública en sus respectivos Estados" (Congreso General Constituyente, 1824, Artículo 50, fracción I).

El texto que se ocupa de la ilustración poco dice de sus fines en los términos de la antropología política del federalismo liberal. Para impulsar el desarrollo de la instrucción se elaboraron varios proyectos y planes sustentados en diversas perspectivas ideológicas, pero entre 1821 y primeros meses de 1833 no hubo legislación. La reforma de las instituciones educacionales en los años de 1833-1834 fue de orientación liberal: secularización, ampliación de la educación preparatoria, educación de adultos, formación de maestros, libertad a la enseñanza privada, creación de una dirección general. El conjunto de leyes que aprobó Gómez Farías disgustó a los conservadores y Santa Ana detuvo la reforma, que fue la primera gran acción del Estado que impulsó la educación (Meneses Morales, 1983). 
Las Leyes Constitucionales de 1836 son normas centralistas y dieron origen a la primera república unitaria, cuyo establecimiento se comprende por los antecedentes de la lucha independentista -insurgencia versus monarquía-, y la disputa posterior a la independencia en torno a las opciones de monarquía constitucional versus república federal o central.

Las Leyes de 1836 expresan el pensamiento conservador que luchó largos años contra los liberales y la Constitución de 1824, pero integraban elementos del liberalismo moderado. La primera de las leyes inició con una «declaración de derechos del mexicanoll y sus deberes, con el propósito de poner fin a los abusos del poder. El cambio constitucional no descuidó la educación; la Sexta Ley dio a las Juntas Departamentales la facultad de «establecer escuelas de primera enseñanza en todos los pueblos de su departamentol, dotándolas de todo lo necesario y añadió la de udictar todas las disposiciones convenientes a la conservación y mejora de los establecimientos de instrucción») (Congreso Nacional, 1836; Artículo 14, fracc. V). La legislación, basada en la creencia de que "la educación del pueblo es el fundamento de su prosperidad" y necesaria para el disfrute de los derechos (López, 1842), impulsó la instrucción obligatoria y la gratuidad de la que ofreciera el Estado.

Las Bases de Organización Política de la República Mexicana (1843) reformaron la Constitución anterior por juzgarla inadecuada para los problemas del país. Acordes con el enfoque centralista de la organización del gobierno, Las Bases dejaron la educación como responsabilidad de los Departamentos y en el gobierno central la instrucción fue ubicada en el Ministerio de Justicia, Negocios Eclesiásticos, Instrucción Pública e Industria, lo que representó un avance en la organización (Junta Legislativa, 1843; artículo 93). Las Asambleas Departamentales, como en 1836, estaban facultadas para crear fondos destinados a la instrucción (artículo 134, IV) y debían fomentar la enseñanza pública (VII).

El Acta Constitutiva y de Reformas (Congreso Extraordinario Constituyente, 1847) se aprobó gracias al fortalecimiento de los liberales y durante sus años de vigencia se continuó el impulso al crecimiento de la instrucción primaria y la preparatoria, así como a la formación de maestros. Se mantuvo la libertad de enseñanza privada con supervisión gubernamental y eclesiástica. En la última dictadura de López de Santa Anna, en 1854, se aprobó el Plan General de Estudios, que puede considerarse el mejor de su tipo hasta ese momento: impulsó la mejora de la instrucción estableciendo que se basara en las ciencias.

Con el triunfo de la revolución de Ayutla, el gobierno de Comonfort mantuvo el cuidado de la instrucción en su Estatuto Orgánico Provisional de la República Mexicana (Comonfort, 1856), lo que muestra que no obstante los problemas políticos y de gobierno, el DEd había echado raíces en la sociedad mexicana.

La segunda transición de México se abre con la Constitución Política de la República Mexicana de 1857, siendo la norma constitucional que hizo el mayor reconocimiento de los derechos fundamentales como "base y objeto de las instituciones sociales" (Congreso Extraordinario Constituyente, 1857; artículo 1). Dada la experiencia social y política de las décadas precedentes, la nueva Ley fundamental pretendía darle estabilidad legal e institucional al país, unificar la nación enraizándose política y culturalmente en el anhelo de independencia de 1810-1821.

Los derechos reconocidos son los principios que dan su nuevo valor ético a la Ley y que originan la exigencia de promover la formación moral correspondiente en los ciudadanos, tanto por la acción cotidiana del Estado como garante de los derechos en el ejercicio del gobierno, como por la vida social democrática y la institución escolar, que habrá de promover el conocimiento, aprecio y vivencia de los principios de la Ley fundamental. La Constitución de 1857 fue innovadora no sólo en lo que concierne a su principio educativo fundamental, la libertad de enseñanza, sino por su proyecto de transformación de la sociedad mexicana fortaleciendo al Estado frente a la soberanía religiosa, con el amplio complemento de las Leyes de Reforma.

Si la Constitución fue una creación culminante del progreso social y político en el reconocimiento de las libertades, la declaratoria constitucional de la libertad de enseñanza abrió el proyecto de formación ciudadana más allá de lo que las leyes fundamentales precedentes lo habían hecho. Esta libertad, por representar la formación de los ciudadanos en una sociedad de derechos, es el 
símbolo más completo de la propia Constitución porque si bien esta sólo dice "La enseñanza es libre" (Congreso Extraordinario Constituyente, 1857; artículo $3^{\circ}$ ), lo hace al interior de su propia naturaleza transformadora: una nueva ética política que incluye el Estado laico. La libertad de enseñanza crea exigencias para el Estado en tanto garante de la misma (Labastida, 1979); para la sociedad, en tanto comunidad democrática en formación y para los ciudadanos, porque su afirmación no es un acto formal aislado y tiene como referente primigenio la soberanía del pueblo, que exige aprender a ejercerla.

En la legislación que se dio entre 1861 y 1910 se impulsó la expansión y mejoramiento de la educación, fundamentalmente en el medio urbano. El rasgo distintivo fue que la educación se ordenó sobre tres principios: gratuidad, obligatoriedad y laicidad, además de la orientación científica. En este rubro es importante destacar que el Estatuto Provisional del Imperio Mexicano, promulgado por Maximiliano, continuó el impulso a la educación con orientación liberal, exceptuando la no laicidad.

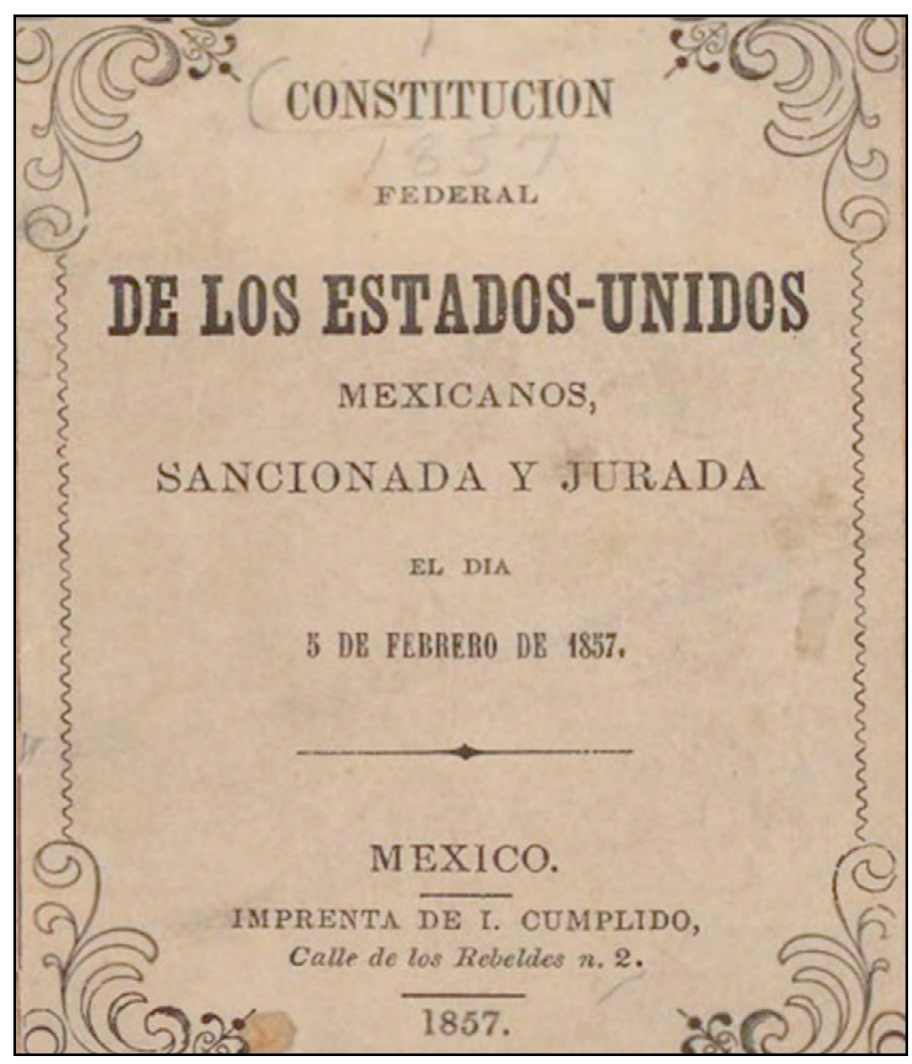

Figura 1. Portada de la edición original de la Constitución de 1857. Imagen tomada de EDUSO (s. f.).
La tercera transición de México fue también impulsada por un conflicto sociopolítico que dio origen a un nuevo orden constitucional caracterizado como social por su atención a las cuestiones obreras y campesinas y un mayor impulso a la educación. La Revolución iniciada por una exigencia política cuya naturaleza inicial parecía resoluble en el régimen jurídico del país -la democracia y el sufragio efectivo-, a causa de la estructura social y económica de la sociedad mexicana y la negación de don Porfirio a abrir la participación política, devino en un proceso de cambio constitucional innovador (Valadés, 2016, p. 36). El proyecto de artículo tercero presentado por Carranza fue breve: reiteraba la libertad de enseñanza de 1857 pero afirmando que sería "plena», y agregaba la laicidad de toda la enseñanza pública y la gratuidad de la primaria.

Los revolucionarios de mayor compromiso social promovieron la modificación del texto para acrecentar la responsabilidad del Estado, de modo que la educación quedó establecida con los siguientes elementos: a) la libertad de enseñanza, b) laicidad de toda la educación, no sólo la pública, c) prohibición de la intervención en la educación -establecer o dirigir escuelas primarias- a las corporaciones religiosas y a los ministros de culto, d) las escuelas primarias particulares quedaban sujetas a vigilancia oficial, y e) la enseñanza primaria oficial gratuita.

La nueva perspectiva jurídica y política hizo que el artículo $3^{\circ}$ se convirtiera en un símbolo axiológico que ha evolucionado a lo largo de los siglos XX y XXI. En el tiempo de la tercera transición incorporó la obligatoriedad de la educación primaria (1934) por un lado y, por el otro, la orientación socialista que adquirió en 1934 fue modificada en 1946, fecha desde la cual conserva su núcleo básico de valores educacionales que dan sentido al DEd. En el intermedio de tales reformas, dos leyes orgánicas impulsaron y regularon el servicio educativo garantizando la igualdad en materia de educación (1940, 1942).

La cuarta transición de México no se inició con una nueva constitución, sino con la creciente demanda social de respetar la existente, la de 1917 , la demanda de vivir el Estado de derecho. Puede comprenderse este proceso de cambio social y político como una revolución cultural que a la postre, en una de sus fases, fue llamada transición a la democracia y tiene varios hechos simbólicos 
desde la década de los sesenta que siguen inspirando y acrecentando la participación política de los mexicanos para reducir, cercar y liquidar el autoritarismo que se resiste aún a someterse al valor de la Ley.

El DEd fue fortalecido en su expresión jurídica, tanto por la afirmación indubitable de que "Todo individuo tiene derecho a recibir educación" (1993) como por el vínculo entre DH y fines de la educación (2011), además de la ampliación de la escolaridad obligatoria desde preescolar hasta bachillerato, así como la precisión de sus rasgos de calidad, tanto en el artículo tercero constitucional como en la LGE. La reforma de 2011 enfatizó la responsabilidad de los gobernantes en la promoción y protección de los DD. HH., lo que ha dado un fundamento de mayor exigencia para la elaboración y aplicación de políticas públicas con orientación de derechos (González Pérez, 2016a, p. 157).

Si cuantitativamente la educación tuvo una gran expansión desde la década de los veinte, en la cuarta transición ha sido la exigencia de formar para la democracia y para el desarrollo equitativo lo que ha caracterizado la demanda social apoyada en el principio-valor de la dignidad humana, fuente de todo derecho.

\section{CONCLUSIONES}

El objetivo del trabajo ha sido exponer los grandes momentos del reconocimiento del derecho a la educación en México. Para ello se estableció una noción de cultura y se identificó su dimensión jurídica y se describieron las transiciones en la formación de México

En todas las formas de gobierno experimentadas por el país y en todas las normas fundamentales se ha manifestado el reconocimiento social y político del derecho a la educación como un bien público. El punto de partida de tal reconocimiento fue que el proyecto de formación de México estuvo fundado en el Estado democrático de derechos.

Las transiciones han logrado avances jurídicos enmarcados en fuertes conflictos sociopolíticos nunca resueltos en forma definitiva, sino progresiva y abierta al cambio social. En ellas, la educación ha sido un elemento clave del proyecto jurídico de nación y de la acción transformadora de la dimensión social y la dimensión político-gubernamental.

Las normas fundamentales en la sucesión de las transiciones de México muestran el continuado esfuerzo del constitucionalismo nacional, a partir de Cádiz y Apatzingán, para establecer el DEd como un bien público que hoy debe garantizarse con calidad y equidad en el marco de la transición a la democracia.

La legislación educativa, al tiempo que muestra variantes en diversos momentos de revisión del proyecto nacional, en el presente recoge valores fundamentales del patrimonio jurídico de México y ofrece una perspectiva renovada de la tarea del Estado como garante del derecho a la educación. 
- Abbagnano, N., \& Visalberghi, A. (1975). Historia de la pedagogía. México: FCE.

- Aboites, H. (2012). El derecho a la educación en México. Del liberalismo decimonónico al neoliberalismo del siglo XXI. Revista Mexicana de Investigación Educativa, 17(53), 361389.

- Braudel, F. (1968). La Historia y las Ciencias Sociales. Madrid, España: Alianza.

- Cámara de Diputados. (2013). Constitución Política de los Estados Unidos Mexicanos. Recuperado de http://www. diputados.gob.mx/LeyesBiblio/htm/1.htm

- Comonfort, I. (1856). Estatuto Orgánico Provisional de la República Mexicana [Documento en pdf]. Recuperado de http://www.ordenjuridico.gob.mx/Constitucion/1856.pdf

- Congreso Extraordinario Constituyente. (1847). Acta Constitutiva y de Reformas [Documento en pdf]. Recuperado de http://www.ordenjuridico.gob.mx/Constitucion/1847.pdf

Mexicana [Documento en pdf]. Recuperado de https:// archivos.juridicas.unam.mx/www/legislacion/federal/ historicos/1857.pdf

- Congreso General Constituyente. (1824). Constitución Federal de los Estados Unidos Mexicanos de 1824 [Documento en pdf]. Recuperado de_https://archivos.juridicas.unam.mx/ www/bjv/libros/4/1671/35.pdf

- Congreso Nacional. (1836). Leyes Constitucionales [Documento en pdf]. Recuperado de http://www. ordenjuridico.gob.mx/Constitucion/1836.pdf

- Cortes de Cádiz. (1812). Constitución política de la Monarquía Española [Documento en pdf]. Recuperado de http://www. ordenjuridico.gob.mx/Constitucion/1812A.pdf

- Cosío Villegas, D. (1947). La crisis de México. Cuadernos Americanos, 32, 29-51.

- De Iturbide, A. (1822). Reglamento Provisional Político del Imperio Mexicano [Documento en pdf]. Recuperado de http://www.ordenjuridico.gob.mx/Constitucion/1823.pdf

- Del Arenal, J. (Ed.). (2002). La Consumación de la Independencia y el Nacimiento del Imperio Mexicano. En J. Z. Vázquez (Coord.), Gran Historia de México. El nacimiento de México. 1750-1856. De las reformas borbónicas a la Reforma (2a. ed., Vol. 3, pp. 121-140). México, D. F.: Planeta-DeAgostiniCONACULTA-INAH
Fix-Fierro, H. (2008). Prólogo. En E. Ferrer y A. Zaldívar (Eds.), La ciencia del derecho procesal constitucional (Vol. 1, pp. 1525). México: UNAM-Instituto Mexicano de Derecho Procesal Constitucional-Marcial Pons.

- Fix-Zamudio, H. (2010). 200 años de evolución constitucional de los derechos humanos en el derecho mexicano. En $M$. C. Fix y M. Á. Quemain (Coords.), 200 años de derechos humanos en México (pp. 11-16). México: CNDH-AGN.

- Frost, E. C. (2009). Las categorías de la cultura mexicana. México: FCE.

- Galván Lafarga, L. E. (2016). Derecho a la Educación. Ciudad de México: Secretaría de Gobernación-Secretaría de Cultura-INEHRM-UNAM. Recuperado de http://www.inehrm. gob.mx/es/inehrm/LLC_2017_Derecho_a_educacion

- Giménez, G. (2007). Estudios sobre la cultura y las identidades sociales. México: CONACULTA-ICOCULT.

- González Domínguez, M. R. (1999). La Constitución política de Cádiz. Análisis Jurídico. En P. Galeana (Ed.), México y sus Constituciones (pp. 24-32). México: AGN-FCE.

- González Pérez, L. R. (2016a). Constitución y Derechos Humanos: Reflexiones para el Siglo XXI. En L. R. González (Coord.), Los derechos humanos en el Centenario de la Constitución de 1917 (pp. 157-173). México: Secretaría de Gobernación-Secretaría de Cultura-INEHRM-UNAM.

$\bullet$ (2016b). Preludio. En L. R. González (Coord.), Los derechos humanos en el Centenario de la Constitución de 1917 (pp. 43-44). México: Secretaría de GobernaciónSecretaría de Cultura-INEHRM-UNAM.

- Instituto Nacional para la Evaluación de la Educación. (2010). El derecho a la educación en México. Informe 2009. México: Autor. (2014). El derecho a una educación de calidad. Informe 2014. México: Autor. (2016). La educación obligatoria en México. Informe 2016. México: Autor.

- Junta Legislativa (1843). Bases Orgánicas de la República Mexicana. Recuperado de http://www.ordenjuridico.gob. $\mathrm{mx} /$ Constitucion/1843.pdf

- Labastida, H. (1979). El Derecho Social a la Educación en México. En E. Álvarez del Castillo (Coord.), Los Derechos Sociales del Pueblo Mexicano (Vol. 2, pp. 103-126). México: Porrúa-Cámara de Diputados. 
- León-Portilla, M. (2005). Aztecas-Mexicas. Desarrollo de una civilización originaria. Madrid, España: Algaba.

- López, A. (1842). Decreto que crea la Dirección General de Instrucción Primaria (pp. 310-312). [Documento en pdf]. Recuperado de http://cdigital.dgb.uanl.mx/ la/1080042593_C/1080043032_T4/1080043032_058.pdf

- Meneses Morales, E. (1983). (Dir.) Tendencias educativas oficiales en México. 1821-1911. México: Porrúa.

- Meyer, L. (1992). La segunda muerte de la Revolución Mexicana. México: Cal y Arena.

•

(2013). Nuestra tragedia persistente. La democracia autoritaria de México. México: Debate-Random House Mondadori.

- $\quad$ Portada de la Constitución Mexicana de 1857] (s. f.). Recuperada de http://www.eduso.net/res/base/imgCK/ images/const1r.jpg

- Rubio, L. (8 de abril de 2018). La vieja-nueva disputa. Reforma, p. 9.

- Ruiz Muñoz, M. M. (2015). Derecho a la Educación: Política y defensa de la escuela pública. México: Universidad Iberoamericana.

- Serrano Migallón, F. (2009). La vida constitucional de México (Vol. 2). México: FCE.
- Soberanes Fernández, J. L. (2012). El pensamiento constitucional en la Independencia. México: Porrúa.

- Solís, P. (2010). La desigualdad de oportunidades y las brechas de escolaridad. En A. Arnaut y S. Giorguli (Eds. de la serie), Serie Los grandes problemas de México: Vol. VII. Educación (pp. 599-657). México, D. F.: El Colegio de México.

- Supremo Congreso Mexicano (1814). Decreto Constitucional para la libertad de la América Mexicana [Documento en pdf]. Recuperado de http://museodelasconstituciones. unam.mx/1917/wp-content/uploads/1814/10/22-octubre1814-Decreto-Const.-para-la-Libertad-de-la-Amer-Mex.pdf

- Valadés, D. (2016). La Constitución y sus grandes temas. En L. E. Galván Lafarga, Derecho a la Educación (pp. 19-37). Ciudad de México: Secretaría de Gobernación-Secretaría de Cultura-INEHRM-UNAM. Recuperado de http://www. inehrm.gob.mx/es/inehrm/LLC_2017_Derecho_a_educacion

- Vázquez, J. Z. (2002). El nacimiento de México. 1750-1856. De las reformas borbónicas a la Reforma. En J. Z. Vázquez (Coord.), Gran Historia de México, 5 vols. (2.a ed., Vol. 3). México: Planeta-DeAgostini-CONACULTA-INAH.

- Woldenberg, J. (2012). Historia mínima de la transición democrática en México. México: El Colegio de México.

- Zárate, J. (1987). La guerra de Independencia. En V. Riva Palacio (Dir.), México a través de los siglos (2.. ed., Vol. 9). México: Cumbre. 